\title{
GEOMETRIC MODELLING OF PORTFOLIO AND RISK IN MARKET EQUILIBRIUM
}

The developing of the financial market contributes to paying attention to analyses its dynamics and quality of properties of the variables. The results of the analysis showed that among the complex technical applications the geometry approach in this area is an advanced method to explain the financial market behaviour. This paper expands the idea that the portfolio is balanced for quotation in marketing is equivalent to the number of points that lie on the quotation hyperplane in projective geometry has been extended in geometric concepts. In this paper, the new geometric approach was proposed to estimate the number of times the portfolio is balanced for quotation. In fact, the calculations were made in terms of the volume of the Halmos-Thomson (as the bridge between Feinsler geometry, integral geometry, and symplectic geometry). The highest number of risks in market equilibrium was mentioned in the geometric concepts mentioned. In this way, the proposed geometric approach allows to analyse situations with a portfolio under different conditions: financial market equilibrium, reduce the risk of investment risk, and others developments in the stock market. The author calculates the parameters through the surface area of a convex body of the corresponding projective spaces and Holmes-Thompson volume in notions of integral geometry (Radon and Fourier transform), Finsler Geometry (and Minkowski spaces) and symplectic geometry. Contrary to existing numerical methods, this approach allows one to reach the analytic solution and also, concludes that the highest number of risks in market equilibrium can be obtained by minimality of the introduced volume.

Keywords: financial market, risk, Minkowski space, Finsler metric, Fourier transform.

Introduction. Today, in the financial market it is important to pay attention to the dynamics and quality of properties of the variables. Among the complex technical applications of geometry in this area is an advanced approach to explaining the financial market behaviour [1-5]. A branch of geometry that is most closely associated with marketing concepts is projective geometry whose main notions of the financial market such as baskets, portfolios and the level of risk taking in market equilibrium can be translated in this framework [4], [6-7].

On the other hand, many problems in geometry and physics can be easily solved by a change of viewpoint. For example, if one considers the line, or the plane, instead of the point as the basic object of geometry, the outlook changes completely. This change in viewpoint leads naturally to integral geometry. This paper is concerned with some analogy of various classical formulas from integral geometry and its relation with Finsler geometry and symplectic geometry.

This deep connection between these three geometries takes place by the type of volume named as Holmes-Thompson volume, [8], which its ties to convex geometry, integral geometry, and Finsler geometry. The other advantage of working with Holmes-Thompson definition is that there is a remarkably simple formula for the Holmes-Thompson area density of a Minkowski space in terms of the Fourier transform of its norm [9-11], which is the main object in this paper.

The first step of this paper contains some preliminaries about Minkowski spaces, Finsler geometry and Integral geometry to cover all the key concepts in its entirety. In the sequel, the application of the triple chain of three geometries in financial markets has been proposed.

The proposed methodology results in the calculation of the number of times that the portfolio is 
balanced for quotation in marketing using the surface area of the convex body and Holmes-Thompson which has been proved in Theorem 1. Contrary to existing numerical methods, this theorem enables one to reach the analytic solution and also, concludes that highest number of risks in market equilibrium can be obtained by minimality of the introduced volume explained in Corollary 1.

Basic geometric concepts. An $n$-dimensional manifold is a set $M$, together with a countable collection of subsets $U_{\alpha} \subset M$ called coordinate charts, and one-to-one functions $\chi_{\alpha}: U_{\alpha} \rightarrow V_{\alpha}$ onto connected open subsets $V_{\alpha} \subset \mathbb{R}^{n}$, called local coordinate maps, which the coordinate charts cover $M ; \cup_{\alpha} U_{\alpha}=M$, on the overlap of any pair of coordinate charts $U_{\alpha} \cap U_{\beta}$ the composite map $\chi_{\beta} \circ \chi_{\alpha}^{-1}: \chi_{\alpha}\left(U_{\alpha} \cap U_{\beta}\right) \rightarrow \chi_{\beta}\left(U_{\alpha} \cap U_{\beta}\right)$ is a smooth (infinitely differentiable) function and distinct points of $M$ separates with distinct open subsets.

A smooth curve $C$ on a manifold $M$ is parametrized by $\phi: I \rightarrow M$, where $I$ is a subinterval of $\mathbb{R}$. In local coordinates $x=\left(x^{1}, \ldots, x^{n}\right), C$ is given by $n$ smooth functions $\phi(\varepsilon)=\left(\phi^{1}(\varepsilon), \ldots, \phi^{n}(\varepsilon)\right)$ of the real variable $\varepsilon$. At each point $x=\phi(\varepsilon)$ of $C$ the curve has a tangent vector, namely the derivative $\dot{\phi}(\varepsilon)=\frac{d \phi}{d \varepsilon}=\left(\dot{\phi}^{1}(\varepsilon), \ldots, \dot{\phi}^{n}(\varepsilon)\right)$.

The collection of all tangent vectors to all possible curves passing through a given point $x$ in $M$ is called the tangent space to $M$ at $x$, and is denoted by $T M_{\mid x}$.

For an $n$-dimensional manifold $M, T M_{\mid x}$ is an $n$-dimensional vector space, with $\left\{\frac{\partial}{\partial x^{1}}, \ldots, \frac{\partial}{\partial x^{n}}\right\}$ providing a basis for $T M_{\mid x}$ in the given local coordinates. The collection of all tangent spaces corresponding to all points $x$ in $M$ is called the tangent bundle of $M$, denoted by $T M=\mathrm{U}_{x \in M} T M_{\mid x}$. A vector field $v$ on $M$ assigns a tangent vector $v_{\mid x} \in T M_{\mid x}$ to each point $x \in M$, with $v_{\mid x}$ varying smoothly from point to point.

The space $\Lambda_{k} T^{*} M_{\mid x}$ of differential $k$-forms at $x$ is the set of all $k$-linear alternating functions $\omega: T M_{\mid x} \times \ldots \times T M_{\mid x} \rightarrow \mathbb{R}$. A (smooth) differential $k$-form $\omega$ on $M$ is a collection of smoothly varying alternationg $k$-linear maps $\omega_{\mid x} \in \Lambda_{k} T^{*} M_{\mid x}$ for each $x \in M$, where for all smooth vector fields $v_{1}, \ldots, v_{k},\left\langle\omega ; v_{1}, \ldots, v_{k}\right\rangle(x) \equiv\left\langle\omega_{\mid x}, v_{1 \mid x}, \ldots, v_{k \mid x}\right\rangle$ is a smooth real-valued function of $x$. For a collection of differential one-forms $\omega_{1}, \ldots, \omega_{k}$, It can be formed a differential $k$-form $\omega_{1} \wedge \ldots \omega_{k}$, using the determinantal formula $\left\langle\omega_{1} \wedge, \ldots, \omega_{k} ; v_{1}, \ldots, v_{k}\right\rangle(x)=\operatorname{det}\left(\left\langle\omega_{i} ; v_{j}\right\rangle\right)$, where the right-hand side being the determinant of a $k \times k$ matrix with indicted $(i, j)$ entry.

Let $\pi: T^{*} M \rightarrow M$ be the standard projection and let $d \pi: T\left(T^{*} M\right) \rightarrow T M$ be its differential. The canonical 1 -form $\alpha$ on $T^{*} M$ is defined by the equation $\alpha\left(V_{P_{m}}\right)=P_{m}\left(d \pi\left(V_{P_{m}}\right)\right.$ ), where $P_{m} \in T_{m}^{*} M$ and $V_{P_{m}} \in T_{P_{m}}\left(T^{*} M\right)$.

The symplectic 2 -form is defined as $\omega=-d \alpha$. A symplectic manifold $(M, \omega)$ is a smooth manifold $M$ of even dimension $2 n$ equipped with a non-degenerate closed 2 -form $\omega$. Note that 2-form $\omega$ on every $2 n$-vector space is non-degenerate if and only if $\omega^{n}$ is a volume form.

Let $V$ be a vector space and $\varphi: V \rightarrow\left[0, \infty\right.$ [ be a norm that is smooth outside the origin. Set $L=\frac{\varphi^{2}}{2}$ and consider the exterior derivative of $L, d L$, as a map from $V \backslash\{0\}$ to $V^{*} \backslash\{0\}$. The norm $\varphi$ is said to be a Minkowski norm if $d L$ is a diffeomorphism.

For any nonzero vector $v \in V$, there is an invertible linear map $D(d L)(v): T_{v} V \rightarrow T_{d L(v)} V^{*}$. In fact, using the natural identification of $T_{v} V$ with $V$, and $T_{d L(v)} V^{*}$ with $V^{*}$, it may be think of $g_{\varphi}(v):=$ $D(d L)(v)$ as a (symmetric) bilinear form on $V: g_{\varphi}(v)\left(\omega_{1}, \omega_{2}\right):=\left(D(d L)(v)\left(\omega_{1}\right)\right)\left(\omega_{2}\right)$.

The norm $g_{\varphi}$ is a Minkowski norm if and only if $g_{\varphi}$ is positive definite. When the vector $v$ belongs to the unit sphere, structure $g_{\varphi}(v)$ denoted as the osculating Euclidean structure at $v$ and the ellipsoid 
$E_{v}:=\left\{w \in V: g_{\varphi}(v)(w, w)=1\right\}$, as the osculating ellipsoid at $v$. A smooth hypersurface in a finitedimensional real vector space $V$ is said to be quadratically convex if its osculating quadrics are all ellipsoids. A vector space $V$ provided with a norm $\|$.$\| such that the unit sphere is quadratically convex$ is called a Minkowski space.

A Finsler metric on a manifold $M$ is a continuous function defined on its tangent bundle such that $\varphi: T M \backslash\{0\} \rightarrow \mathbb{R}$ is smooth (away from the zero section) and its restriction to each tangent space is a Minkowski norm, means that the hypersurface $S_{m} M:=\left\{v \in T_{m} M: \varphi(v)=1\right\}$ is quadratically convex and encloses the origin, $(M, \varphi)$ is called a Finsler manifold.

Throughout this paper, $M$ is a compact manifold and for every $m \in M$ and any compact hypersurface $H \subset T^{*} M$, the intersection $H \cap T^{*} M$ is a convex hypersurface of $T_{m}^{*} M$ enclosing the origin and in each cotangent space $T_{m}^{*} M$ the intersection $H \cap T^{*} M$ is a quadratically convex hypersurface enclosing the origin. In this way, it can be defined the Holmes-Thompson volume:

The Holmes-Thompson volume of a $n$-dimensional Finsler manifold $(M, \varphi), \operatorname{vol}_{n}(M, \varphi)$, is the symplectic volume of its unit co-disc bundle divided by the volume of the Euclidean $n$-dimensional unit ball

$$
\operatorname{vol}_{n}(M, \varphi)=\frac{1}{\varepsilon_{n} n} \int_{S_{H}^{*} M} \alpha \wedge(d \alpha)^{n-1},
$$

where $\varepsilon_{n}$ is the volume of the Euclidean unit ball of dimension $n$.

Let $K$ is a convex body. Then it admits at least one supporting hyperplane $H$ (affine here) for any point $x$ of its boundary. The dual convex body $K^{*}$ of a given convex body $K$ is either the convex hull of the poles of the supporting hyperplanes of $H$.

If the convex body $K$ be star-shaped with respect to origin in $\mathbb{R}^{n}$ and the boundary of $K$ is continuous in the sense that the Minkowski functional of $K$ defined by $\|x\|_{K}=\min \{a \geq 0: x \in a K\}$ is a continuous function on $\mathbb{R}^{n}$, then the Minkowski functional is a homogeneous function of degree 1 on $\mathbb{R}^{n}$ is strictly positive outside of the origin, and $\mathrm{K}=\left\{x \in \mathbb{R}^{n}:\|x\|_{K} \leq 1\right\}$.

The radial function of a star body $\mathrm{K}$ is defined by $\rho_{K}(x)=\|x\|_{K}^{-1}, x \in \mathbb{R}^{n}$. If $x \in S^{n-1}$., then $\rho_{K}(x)$ is the radius of $\mathrm{K}$ in the direction of $x$, i.e., the distance from the origin to the boundary of $K$ in the direction of $x$.

Lemma 1 [12]. Let $K$ be an origin-symmetric star body in $\mathbb{R}^{n}$. Then, for $0<p<n$, the function $\|.\|_{K}^{-p}$ is locally integrable on $\mathbb{R}^{n}$. Also, if $f$ is a bounded integrable function on $\mathbb{R}^{n}$, then the function $\|\cdot\|_{K}^{-p} f($.$) is integrable on \mathbb{R}^{n}$.

In this way, for $\xi \in S^{n-1}$ can be defined the parallel section function of $K$ in the direction of $\xi$ as a function on $\mathbb{R}$ given by $A_{K, \xi}(t)=\operatorname{vol}_{n-1}\left(K \cap\left\{\xi^{\perp}+t \xi\right\}\right)$ where $\left\{\xi^{\perp}+t \xi\right\}$ is the hyperplane perpendicular to $\xi$ at distance $t$ from the origin and can be stated as the following: $A_{K, \xi}(t)=\int_{\langle x, \xi\rangle=t} \chi\left(\|x\|_{K}\right) d x$ which $\chi\left(\|.\|_{K}\right)$ is the indicator function of the body $K$. For $t=0$, writing the integral in the right-hand side of the function $A_{K, \xi}(t)$ in the polar coordinates of the hyperplane $\langle x, \xi\rangle=0$, result in the polar formula for the volume of central hyperplane sections 


$$
\begin{gathered}
A_{K, \xi}(0)=\operatorname{vol}_{n-1}\left(K \cap \xi^{\perp}\right)= \\
\int_{\langle x, \xi\rangle=t} \chi\left(\|x\|_{K}\right) d x=\int_{S^{n-1} \cap \xi^{\perp}}\left(\int_{0}^{\infty} r^{n-2} \chi\left(r\|\theta\|_{K}\right) d r\right) d \theta \\
=\int_{S^{n-1} \cap \xi^{\perp}}\left(\int_{0}^{\frac{1}{\|\theta\|_{K}}} r^{n-2} d r\right) d \theta=\frac{1}{n-1} \int_{S^{n-1} \cap \xi^{\perp}}\|\theta\|_{K}^{-n+1} d \theta= \\
\frac{1}{n-1} \int_{S^{n-1} \cap \xi^{\perp}} \rho_{K}^{n-1}(\theta) d \theta
\end{gathered}
$$

If $\phi$ be an integrable function on $\mathbb{R}^{n}$, which is also integrable on every hyperplane, then the Radon transform of the function $\phi$ is defined as a function of $(\xi ; t), \mathcal{R} \phi(\xi ; t)=\int_{\langle x, \xi\rangle=t} \phi(x) d x, \xi \in S^{n-1}$, $t \in \mathbb{R}$.

Using (2), one can express the volume of central hyperplane sections in terms of the spherical Radon transform:

$$
A_{K, \xi}(0)=\operatorname{vol}_{n-1}\left(K \cap \xi^{\perp}\right)=\frac{1}{n-1} \mathcal{R}\left(\|\cdot\|_{K}^{-n+1}\right)(\xi)
$$

for every origin-symmetric star body $K$ in $\mathbb{R}^{n}$ and every $\xi \in S^{n-1}$. Furthermore, for $(n-1)$ - dimensional linear subspaces of $\mathbb{R}^{n}$, instead of $\xi^{\perp}$, the spherical Radon transform is self-dual, means that for any function $f, g \in C\left(S^{n-1}\right)$;

$$
\int_{S^{n-1}} \mathcal{R} f(\xi) g(\xi) d \xi=\int_{S^{n-1}} f(\xi) \mathcal{R} g(\xi) d \xi
$$

There is a well-known connection between the Radon and Fourier transform,

Lemma 2 [12]. For a fixed $\xi$, the Fourier transform of the function $g(t)=\mathcal{R} \phi(\xi ; t), t \in \mathbb{R}$ is equal to the function $z \rightarrow \hat{\phi}(z \xi), z \in \mathbb{R}$.

The Fourier transform of distributions is the main tool used the proof of Theorem 1 in the sequel. For more details about the concepts mentioned in this sections can be referred to the refrences [12-20].

Applications of geometry in financial markets.

The market determines what goods are made and what products are bought and sold. It is assumed that the objects of investors' interest span a $(n+1)$ - dimensional vector space $V$ over the reals. Elements of this vector space are called baskets.

For any basket, there is a unique representation in elements of the basis of the vector space $V$ which coefficients are called as assets of the basket. A portfolio is defined as an equivalence class of non-empty baskets.

A Market quotation is a functional on the vector space $V$ which associates with a given portfolio, its current value in units of the coefficients of its representation in elements of the basis. It has been said that a portfolio is balanced for some quotation if there is an asset, so that the value of the portfolio in units of the asset is zero.

Equivalently, in more specialized concepts of financial recourse, it can be said that a portfolio is balanced if the corresponding point belongs to the hyperplane representing quotation. The correspondence between the parameters discussed can be seen in Table 1. 
Table 1 - Correspondence between financial market parameters and projective geometry [7]

\begin{tabular}{|c|c|}
\hline Market & Projective Geometry \\
\hline portfolio & point \\
\hline quotation & hyperplane \\
\hline portfolio is balanced for quotation & point lies in quotation hyperplane \\
\hline
\end{tabular}

In completing Table 1, the following statement can be proved.

Theorem 1. The number of times that portfolio is balanced for quotation in marketing (which has been assessed by the point lies in quotation hyperplane in projective geometry) can be calculated by the surface area of the convex body and (symplectic) Holmes-Thompson volume in notions of Fourier transform, Finsler metrics and Minkowski spces.

Proof. Using of Lemma 1, Lemma 2 and self-duality of spherical Radon-transform, relation (4), it can be achieved the connection between the volume of sections of symmetric star bodies and the Fourier transform:

If $f$ be an even homogeneous function of degree $-n+1$ on $\mathbb{R}^{n}$ and continuous on the sphere $S^{n-1}$, then the Fourier transform of $f$ is even homogeneous of degree -1 and continuous on $\mathbb{R}^{n} \backslash\{0\}$ function such that, for every $\xi \in S^{n-1}, \mathcal{R} f(\xi)=\int_{S^{n-1} \cap \xi^{\perp}} f(\theta) d(\theta)=\frac{1}{\pi}(\hat{f}(\xi))$.

In this way, and by relation (3), it can be concluded that if $K$ is an origin-symmetric star body in $\mathbb{R}^{n}$, then the Fourier transform of the function $\|.\|_{K}^{-n+1}$ is homogeneous of degree -1 function on $\mathbb{R}^{n}$ and continuous on $\mathbb{R}^{n} \backslash\{0\}$ such that, for every $\xi \in S^{n-1}$, $A_{K, \xi}(0)=\operatorname{vol}_{n-1}\left(K \cap \xi^{\perp}\right)=\frac{1}{\pi}(n-1)\left(\mathcal{F}\left(\|.\|_{K}^{-n+1}\right)(\xi)\right)$.

If $(V, \phi)$ is an $n$-dimensional Minkowski space and $N \subset V$ is an immersed submanifold of dimension $k, 1 \leq k<n$, then the formula for the Holmes-Thompson $k$-area of $N$ will be $\operatorname{vol}_{k}(N)=\frac{1}{\varepsilon_{k}}\left(\int_{N} \phi_{k}\right)$, where $\varepsilon_{k}$ denotes the volume of the Euclidean unit ball of dimension $k$, $\phi_{k}\left(v_{1} \wedge \ldots \wedge v_{k}\right):=\int_{\left(\xi_{1} \wedge \ldots \wedge \xi_{k}\right) \in S^{*}}\left|\xi_{1} \wedge \ldots \wedge \xi_{k} . v_{1} \wedge \ldots \wedge v_{k}\right| \check{\phi}^{k}, S^{*}$ is any closed hypersurface in $V^{*} \backslash\{0\}$ that is star-shaped with respect to the origin and $\left.\breve{\phi}^{k}=-\frac{1}{4}(2 \pi)^{n-1}\left(\phi d \xi_{1} \wedge \ldots \wedge d \xi_{n}\right)\right\rfloor X_{E}$ is the contraction of standard (distributional) Fourier transform of $\phi$ with the Euler vector field $X_{E}(\xi)=\xi$ in $V^{*}$.

In effect, there exists a smooth, translation-invariant, and possibly signed measure $\Phi_{n-k}$ on the manifold $\mathrm{H}_{n-k}$ of $(n-k)$-flats of $V$ such that if $N \subset V$ is an immersed $k$-dimensional submanifold. Then

$$
\operatorname{vol}_{k}(N)=\frac{1}{\varepsilon_{k}}\left(\int_{\lambda \in H_{n-k}} \operatorname{Cardinality}(N \cap \lambda) \Phi_{n-k},[21-22]\right.
$$

where $\varepsilon_{k}$ is the volume of the Euclidean unit ball of dimension $k$.

Eventally, for a projective Finsler metric $\varphi$ on an open convex domain $D \subseteq \mathbb{R} P^{n}$ and a natural number $k, 1 \leq k \leq n-1$, equation (5) is satisfied with $D$ instead of $(V,\|\|$.$) , that means$ 
$\operatorname{vol}_{k}(N)=\frac{1}{\varepsilon_{k}}\left(\int_{\xi \in H_{n-k(D)}} \operatorname{Cardinality}(N \cap \lambda) \Phi_{n-k},\right.$.

The results are summarized in Table 2.

Table 2 - Computation of corresponding financial market parameters and projective geometry

\begin{tabular}{|c|c|}
\hline Market & Projective Geometry \\
\hline portfolio & point \\
\hline quotation & hyperplane \\
\hline portfolio is balanced for quotation & point lies in quotation hyperplane \\
\hline $\begin{array}{c}\text { number of times that portfolio is } \\
\text { balanced for quotation }\end{array}$ & $\begin{array}{c}\text { surface area of convex body and (symplectic) } \\
\text { Holmes-Thompson volume in notions of Fourier } \\
\text { transform, Finsler metrics and Minkowski spces }\end{array}$ \\
\hline
\end{tabular}

Corollary 1. The highest number of risks in market equilibrium can be obtained by the minimality of the volume in corresponding notions of geometry.

Proof. As the proof of Theorem 1, formula (5) for the Holmes-Thompson volume implies that the tangent spaces of a projective Finsler metric are hypermetric if and only if the measures $\Phi_{n-k}$, $k=1, \ldots, n$, are projective. Then, just like in the case of the standard Riemannian metric on $\mathbb{R} P^{n}$, projective subspaces are area-minimizing. By adding risk calculations, Table 2 can be completed in Table 3.

Table 3 - Computation of risk and the other corresponding financial market parameters and projective geometry

\begin{tabular}{|c|c|}
\hline Market & Projective Geometry \\
\hline portfolio & point \\
\hline quotation & hyperplane \\
\hline portfolio is balanced for quotation & point lies in quotation hyperplane \\
\hline $\begin{array}{l}\text { number of times that portfolio is balanced for } \\
\text { quotation }\end{array}$ & $\begin{array}{l}\text { surface area of convex body and (symplectic) } \\
\text { Holmes-Thompson volume in notions of Fourier } \\
\text { transform, Finsler metrics and Minkowski spces }\end{array}$ \\
\hline highest number of risks in market equilibrium & $\begin{array}{l}\text { minimality of the volume in corresponding notions of } \\
\text { geometry }\end{array}$ \\
\hline
\end{tabular}

Conclusions. In this paper, a new geometric approach was presented to calculate the number of times hat portfolio is balanced for quotation. In fact, the calculations were made in terms of the volume of the Halmos-Thomson (as the bridge between Feinsler geometry, integral geometry, and symplectic geometry). The highest number of risks in market equilibrium was mentioned in the geometric concepts mentioned. In this way, the proposed geometric approach can provide an appropriate answer to many marketing issues such as financial market equilibrium, reduce the risk of investment risk, and other developments in the stock market. 
Henry-Labordère, P., Analysis, Geometry, and Modeling in Finance Advanced Methods in Option Pricing, CRC Press, Taylor \& Francis Group, 2009.

Swishchuk, A. and Islam, S., Random Dynamical Systems in Finance, Taylor and Francis Group, 2013.

Farinelli, S., Geometric arbitrage theory and market dynamics, American Institute of Mathematical Sciences, 7(4), 2015, 431-471.

Zabreiko, P.P. and Lebedev, A.V., Banach geometry of financial market models. Doklady Mathematics, 95(2), 2017, 164-167.

Chile, S., Random Geometric Analysis in the Stochastic Volatility: Financial Markets States Degeneracy, Analysis and Computations Journal, Forthcoming, 2017, SSRN: https://ssrn.com/abstract=2968295.

Piotrowski, E.W. and Stankowski, J., Geometry of Financial Markets - Towards Information Theory Model of Markets, Physica A: Statistical Mechanics and its Applications, 382(1), 2007, 228-234.

Piotrowski, E.W. and Stankowski, J., The merchandising mathematician model: profit intensities, Physica A: Statistical Mechanics and its Applications, 318(3-4), 2003, 496-504.

Holmes, R.D. and Thompson, A.C., N-dimensional area and content in Minkowski spaces, Pacific Journal of Mathematics, 85(1), 1979, 77-110.

Paiva, J.C.A. and Fernandes, E., Fourier transforms and Holmes-Thompson volume of Finsler manifolds, International Mathematics Research Notices, 1999(19), 1999, 1031-1042.

Paiva, J.C.A. and Thompson, A.C., Volumes on normed and Finsler spaces, Chapter book of a Sampler of Riemann-Finsler Geometry, Cambridge University Press, 2004, 1-48

Paiva, J.C.A., Some problems on Finsler geometry, Handbook of Differential Geometry, vol. 2, 2006, 1-33

Koldobsky, A., Fourier Analysis in Convex Geometry, American Mathematical Society, vol. 116, 2006.

Benjani, A.A., Finsler geometry and applications, Ellis Horwood, 1996.

Besse, A., Manifolds of all whose geodesics are closed, Springer-Verlag, New York, 1978.

Gelfand, I.M and Smirnov, M., Lagrangians satisfying Crofton formulas, Radon transforms, and nonlocal differentials, Advances in Mathematics, 109(2), 1994, 188-227.

Gromov, M., Filling Riemannian manifolds, Journal of Differential Geometry, 18(1), 1998, 1-147.

Rudin, W., Functional Analysis, Mc Graw-Hil. New York, 1973.

McDuff, D. and Salamon, D., Introduction to symplectic topology, Oxford Mathematical Monographs, Clarendon Press, 1998.

Dym, H. and McKean H.P., Fourier series and Integrals, Academic Press, New York, 1972.

Schneider, R., On integral geometry in projective Finsler spaces, Izvestiya Natsional'noi Akademii Nauk Armenii. Matematika, 37, 2002, 34-51.

Schneider, R. and Wieacker, J.A., Integral geometry in Minkowski spaces, Advances in Mathematics, 129(2), 1997, 222-260.

Paiva, J.C.A. and Fernandes, E., Crofton formulas in Projective Finsler spaces, Electronic Research Announcements of the American Mathematical Society, 4, 1998, 91-100.

A. Хасан-Задех, Ph.D., Технічний інститут, Тегеранський університет (Гуйлан, Іран).

Геометричне моделювання ризику інвестиційного портфелю в умовах ринкової рівноваги

Стрімкий розвиток фінансового ринку обумовлює необхідність пошуку інноваційних інструментів аналізу його динаміки та основних параметрів функціонування. Результати аналізу показали, що серед складних технічних підходів пояснення поведінки фрінансового ринку перспективним методом є геометричний. Автор розширює традиційні підходи до аналізу фрінансового ринку, пропонуючи власну інновацію: він стверджує, що оцінювання збалансованост інвестиційного портфелю в умовах рівноважної ринкової економіки можливе в рамках геометричних понять. У даній роботі запропоновано інноваційний геометричний підхід до оцінювання рівня збалансованості та ризикованост інвестиційного портфелю в умовах ринкової рівноваги. Розрахунки проводились за допомогою методу Галмоша-Томсона (як перехідного методу між геометрією Фейнслера, інтегральною геометрією та симплектичною геометрією). Найбільша кількість ризиків у ринковій рівновазі описується саме в геометричних концепціях. Таким чином запропонований геометричний підхід дозволяє аналізувати ситуації з інвестиційним портфелем в різних умовах: рівновага фінансового ринку, зменшення інвестиційного ризику та інші події на фоондовому ринку. Автор розраховує параметри фондового ринку через площу поверхні випуклого тіла відповідних проективних просторів та об'єму ХолмсаТомпсона в поняттях інтегральної геометрії (перетворення Радона і Фур'є), Фінслерової геометрії (i просторів Мінковского) та симплектичної геометрії. На відміну від існуючих чисельних методів, даний підхід дозволяє отримати 
аналітичне рішення, а також висновок про те, що найбільшу кількість ризиків при ринковій рівновазі можна отримати при мінімальному обсязі інвестиційного портфелю.

Ключові слова: фінансовий ринок, ризик, простір Мінковського, метрика Фінслера, перетворення Фур'є.

http://mmi.fem.sumdu.edu.ua/en 